\title{
Tuberculosis as a Reason for Male and Female Sexual Dysfunction
}

\author{
Kulchavenya $E^{1,2^{*}}$, Osadchiy $A^{1}$ and Khomyakov $\mathbf{V}^{1}$ \\ ${ }^{1}$ Novosibirsk Research TB Institute, Novosibirsk, Russian Federation \\ ${ }^{2}$ Novosibirsk Medical University, Novosibirsk, Russian Federation \\ "Corresponding author: Ekaterina Kulchavenya, Novosibirsk Research TB Institute, Novosibirsk, Russian Federation, Tel: +79137830382; E-mail: \\ ku_ekaterina@mail.ru
}

Received date: May 22, 2017; Accepted date: January 31, 2018; Published date: February 05, 2018

Copyright: (c) 2018 Kulchavenya E, et al. This is an open-access article distributed under the terms of the Creative Commons Attribution License, which permits unrestricted use, distribution, and reproduction in any medium, provided the original author and source are credited.

\begin{abstract}
Tuberculosis (TB) is one of the greatest infectious killers worldwide for adult. In 2014, TB killed 1.5 million people (1.1 million HIV-negative and 0.4 million HIV-positive). Eighty percent of male patients with pulmonary TB are young men, and reproductive function is extremely important for them. The problem of the influence of pulmonary tuberculosis on the sexual function in men has been covered in medical literature insufficiently and most publications devoted to urogenital tuberculosis (UGTB) as well as for female genital tuberculosis (FGTB). Some articles demonstrates negative influence on reproductive function not only TB as infection disease, but as well anti-TB drugs.

Tuberculosis disturbs sexual function including reproductive one both in male and female patients-and not only TB of genitals, but also pulmonary TB. TB patients have to take not less than 4 anti-TB drugs simultaneously for a long time and anti-TB drugs negative influence on sexual function too. It is necessary to have high index of suspicion for in-time diagnosis of genital TB. Protective pathogenetic therapy is indicated for TB patients.
\end{abstract}

Keywords: Tuberculosis; Male; Female; Urogenital; Genitals; Infertility; Sexual; Reproductive; Sexual dysfunction

\section{Introduction}

Tuberculosis (TB), one of the deadliest diseases is shattering the health and socioeconomic status of the society. The emergence of multidrug resistant (MDR) and extremely drug resistant (XDR) strains has provided unprecedented lethal character to TB [1]. From year to year a number of patients with TB are increasing. Co-infection with human immunodeficiency virus (HIV) makes prognosis worse. In 2014, TB again killed 1.5 million people (including 400000 HIVpositive). Epidemic tendency on TB is negative: during 3 years (from 2012 until 2014) incidence increased from 8.6 million people to 9.6 million people, and mortality-from 1.3 million to 1.5 million [2-5]. Given that most deaths from TB are preventable, the death toll from the disease is unacceptably high.

World Health Organization (WHO) recognized tuberculosis (TB) as a global problem, but meant mostly pulmonary TB. Urogenital Tuberculosis (UGTB) is the second-third most common extra-pulmonary manifestation of tuberculosis (TB) and an isolated involvement of genital organs are reported in $5-30 \%$ of the cases [6]. While Urogenital TB is also important, as $77 \%$ men died from all forms of TB, had prostate TB, mostly overlooked alive [7-9]. We cannot ignore prostate TB because it may be as a sexually transmitted disease [10]. Genital TB, both female and male, lead to infertility and decreased a sexual function as whole that reduces a quality of life $[9,10]$. Prostate TB actually is prostatitis, and like any other prostatitis may result in chronic pelvic pain, that significantly reduces a quality of life again [11].

The good sexual life is an integral part of full and happy life of modern human, but some diseases disrupt it. So, $42-67.3 \%$ of patients with diabetes and high blood pressure have sexual dysfunction [12-15]. The majority of TB patients are young men and sexual function is very important for them. Tuberculosis significantly disturbs patients mentally and physically. Chronic infection, long isolation, intake of big quantity of drugs leads to sexual dysfunction including infertility. Female genital tuberculosis as well is one of the leading reasons for reproductive dysfunction.

\section{Material and Methods}

A Medline/PubMed research with key words "tuberculosis sexual dysfunction" resulted in nothing-there were none paper dedicated to this problem. A Medline/PubMed research with key words "genital tuberculosis" resulted in a total of 3418 titles, 414 within the last 10 years (since 2007), and 207 within the last 5 years (since 2012). A Medline/PubMed research with key words "male genital tuberculosis" resulted in a total of 980 titles, 148 within the last 10 years (since 2007), and 59 within the last 5 years (since 2012). A Medline/PubMed research with key words "female genital tuberculosis" resulted in a total of 2593 titles, 258 within the last 10 years (since 2007), and 131 within the last 5 years (since 2012). So, female genital tuberculosis is more popular topic (Table 1). All articles with key words "genital tuberculosis infertility" were included in the link of papers with key words "genital tuberculosis".

Among 414 articles with key words "genital tuberculosis" of the last 10 years, 163 (39.4\%) were case reports, including cases of Tuberculous epididymorchitis and prostatitis following intravesical BCG for superficial bladder cancer, $82(19.8 \%)$ mentioned genital tuberculosis in the context of other diseases, 60 articles (14.5\%) were dedicated to infertility, mostly female, 48 (11.6\%) were associated with human immunodeficiency (HIV) virus infection, 37 papers $(8.9 \%)$ were dedicated to diagnostic of genital tuberculosis, 24 articles (5.8\%) were 
dedicated to therapy, including with multi-drug resistant $M$. tuberculosis, describing the experience of single centers. To estimate the influence tuberculosis on sexual function worldwide was almost impossible; most studies have been published under this topic in Russian.

\begin{tabular}{|l|l|l|l|}
\hline Search results & with key words "genital tuberculosis" & $\begin{array}{l}\text { with key words “male genital } \\
\text { tuberculosis" }\end{array}$ & $\begin{array}{l}\text { with key words "female genital } \\
\text { tuberculosis" }\end{array}$ \\
\hline total & 3418 & 980 & 2593 \\
\hline Within $2007-2017$ & 414 & 148 & 258 \\
\hline Within $2012-\mathbf{2 0 1 7}$ & 207 & 59 & 131 \\
\hline
\end{tabular}

Table 1: Papers on genital tuberculosis, cited in Medline/PubMed.

Sixty literature issues dedicated to problem of TB and infertility as whole, problem of influence of the environmental pollution and bad behavior on the ejaculate, connection with both male female infertility and tuberculosis as well as negative influence of tuberculosis and its therapy on sexual function were analyzed and structured.

\section{Results}

\section{The significance of tuberculosis}

According to WHO data, about 3 million persons throughout the world have latent tuberculosis, which means people have been infected by Mycobacterium tuberculosis (Mtb). People infected with Mtb have a lifetime risk of falling ill with TB of $10 \%$. There are some factors which increase a risk of the development TB: compromised immune systems (for example, HIV-infection), malnutrition or diabetes, using tobacco, alcohol etc [2-5]. TB is a leading killer of people living with HIV causing one fifth of all deaths [2-5].

Eighty percent of male patients with pulmonary TB are young men [16-18]. The problem of the influence of pulmonary tuberculosis on the sexual function in men has been covered in medical literature insufficiently and most publications devoted to urogenital tuberculosis (UGTB) as well as for female genital tuberculosis (FGTB).

\section{The problem of infertility}

Fertility problems are observed in a growing number of couples in many countries $[19,20]$. A couple is considered as infertile if they have been trying to conceive for more than one year without success. In about $40 \%$ to $50 \%$ of couples subfertility may be a result of female problems, including ovulatory disorders, poor oocyte quality, fallopian tube damage and endometriosis-as well as tuberculosis [21-23]. Actually fertility is a combine problem of a couple. Now male fecundity (his biological capacity to reproduce) ranks as a component of the fertility rate too [24]. A dramatic decline in semen quality over the past half-century has been found [25].

It was found, that only $23 \%$ of 4867 health young Danish men had optimal sperm concentration and sperm morphology. Authors compared the historic data of men attending a Copenhagen infertility clinic in the 1940s and men who recently became fathers. Both these groups had significantly better semen quality than general male population now-a-days [21]. The reduced semen quality may require for assisted reproduction $[22,23]$.

Male infertility is a common and complex problem affecting 1 in 20 men, and reasons for that are mostly unknown. There is an opinion, that epigenetic factors play a significant role in male infertility and should be studied extensively [24].

\section{Influence of the environmental pollution and wrong behavior on the ejaculate}

An increasing number of reports suggest that chemical and physical agents in the environment, introduced and spread by human activity may affect male fertility in humans [25]. It was proved that smokers compared with non-smokers, had a significant decrease in semen volumes, worsening of motility and sperm viability. As well smokers had a noticeably more high level of immotile sperms and more leukocytes [26]. Of $30 \%$ to $80 \%$ of male subfertility cases are considered to be due to the damaging effects of oxidative stress on sperm [27]. Concurrent alcohol exposure has been associated with reduced fecundity. It was shown, that consume of alcohol by pregnant woman may have hurt Sertoli cells in her sons, and thereby negatively effect on further sperm concentration in his ejaculate [28]. Probably the cumulative effects of various low-dose exposures in our environment are responsible for the disorder in the male reproductive system. Semen quality may be the most sensitive marker of adverse environmental exposures [29].

\section{The influence of urogenital infections and inflammation on fertility}

The influence of urogenital infections and inflammation on fertility is still not well known, but $5-12 \%$ of men attending infertility clinics had urogenital inflammation in history [30-32]. Infection has a detrimental effect on sperm quality by reducing of concentration and motility, also urogenital infections may affect the number of morphological normal spermatozoa. Outcome of urogenital infection often is fibrosis that may cause obstruction most likely located in the ejaculatory ducts $[33,34]$.

Chronic prostatitis may cause scarring of the prostatic and ejaculatory ducts, resulting in low seminal volume with low fructose and alpha-glucosidase-important components of fertile ejaculate [30]. Half of patients presenting with $<1$ million spermatozoa per milliliter of ejaculate have no a normal spermatogenesis and $10 \%$ of patients with abnormal spermatogenesis had echo-signs of prostatitis: transrectal ultrasound of the prostate revealed various abnormalities: oedema, dilatation of the seminal vesicles and ejaculatory ducts, intraprostatic calcifications and dilatation of the periprostatic venous plexus. Among them $12 \%$ had a history of male accessory genital infection Ejaculatory duct obstruction due to inflammation is a 
common cause of male infertility, and infections are present in at least $22-50 \%$ of these men [35].

\section{Male infertility and tuberculosis}

Infertility is one of the most common symptoms of genital tuberculosis-both male and female. Infertility may even be a first symptom of male genital tuberculosis [36,37]. Lübbe et al. [37] reported a case of a 26-year-old patient who addressed to a clinic because of primary infertility. His examination revealed leukocytospermia, but sperm count was normal. Authors had high index suspicion on UGTB, and investigated morning urine on Mtb by culture. Positive result confirmed the diagnosis of UGTB.

The epididymis are the commonest involved organs affected primarily by a hematogenous mode of spread. TB is characterized by extensive destruction and fibrosis, so only early diagnosis and a therapy may prevent function and organ loss [6]. Tuberculous epididymitis is often cause of infertility [38-41]; the development of excretory-obstructive forms of infertility as a result of male genital tuberculosis was also reported $[36,37,42]$. Sonographic findings such as the heterogeneous and hypoechoic swelling of the epididymis or the concomitant hypoechoic lesion of the testis with associated sinus tract or extratesticular calcifications are typical for tuberculous epididymitis and orcho-epididymitis, and may explain the nature of infertility in MGTB patients [43-46]. MGTB especially TB epididymitis provide a high risk of male infertility secondary to vasal or epididymal obstruction or testicular necrosis [44].

Late diagnosed TB epididymitis has less chance for recurrence by chemotherapy and may be indicated for surgery and lead to sterility [5]. Vasovasostomy or vasoepididymostomy performed after recurrence from UGTB have low efficiency [46].

A typical case of azoospermia due to UGTB was reported [43]. A 38-year-old man had a history of 4-year infertility. Earlier he had urogenital tuberculosis, and was successfully cured. Calcifications in the seminal vesicles and nodules in the right epididymis were found. An obstructive azoospermia was estimated as an outcome of urogenital tuberculosis as well as a complication of anti-TB therapy. A sperm was extracted from his testis (testicular sperm extraction) and fertilized his wife's ovocyte by intracytoplasmic sperm injection was performed [43]. Moon et al. [33] estimated embryo quality and pregnancy outcome after intracytoplasmic sperm injection (ICSI) in patients with obstructive azoospermia due to previous tuberculous epididymitis. Authors concluded that previous TB epididymitis in patients with obstructive azoospermia does not affect the outcome of sperm retrieval and ICSI [33].

Not only Mtb may cause a male infertility, but also infection with non-tuberculous mycobacterium. Indudhara et al. [34] presented a case of diabetic patient with seminal vesiculitis due to Mycobacterium gastri and male infertility. The improvement in semen quality after 6 months of anti-TB therapy with isoniazid, ethambutol and rifampicin authors estimated as a confirmation of etiologic role of nontuberculous mycobacterium in male infertility.

Fraietta et al. [39] described a case of aspermia as a complication of TB of seminal vesicles. Tzvetkov [44] have analyzed history cases of 69 MGTB patients. TB epididymitis was diagnosed in $78.26 \%$ : unilateral affection was evident in $68.12 \%$ of patients, and frequency of involvement of left and right sites was similar. In $40.58 \%$ of patients, various alterations of sperm quality were diagnosed. Almost one-third of cases showed co-morbidity and $36.24 \%$ were associated with TB of other organs and systems. Authors concluded that MGTB has a considerable impact on fertility and still remains a challenging medical problem [44].

Sole-Balcells et al. [42] investigated spermiogram in 50 young (under 40 years old) UGTB patients. All were divided into two groups: the first one included patients with genital TB, and the second one included patients with isolated kidney TB. All patients with male genital tuberculosis, showed alterations in the cytomorphological and/or in the biochemical characteristics of ejaculate. In the group of kidney TB, 75\% of the patients showed oligoasthenozoospermia too, in spite of they had no genital involvement. Anti-TB therapy did not result in the improvements of the quality of ejaculate in both groups. Other authors received the same data [42].

\section{Female infertility and tuberculosis}

Tuberculosis is one of the commonest causes of both male and female infertility in developing countries. Sheikh [45] reported a woman with primary infertility. The patient underwent laparoscopy, and peritoneal tubercles and fluids were found. The tubercles were covering the viscera so extensively that identity of intra-abdominal organs was impossible. The diagnosis was confirmed by culture.

Female genital tuberculosis is common disease in India-and it is common reason for female infertility there [46]. A total of 85 infertile women with chronic pelvic pain underwent diagnostic laparoscopy; in all genital TB was confirmed. Authors considered a significant pelvic morbidity, fibrosis and tubal damage as main reason for infertility in FGTB patients [46].

Singh et al. [47] also think that genital tuberculosis is the major causative factor for severe tubal disease requiring assisted reproduction in developing countries like India. Earlier Parikh et al. [48] noted that the tuberculosis, a chronic infectious disease, is one of the major etiologic factors of female tubal infertility, especially on the Indian subcontinent again.

Tripathy [49] considered infertility as a complication of female genital TB (mostly due to tubal factor), and have found this in $58 \%$ of infertile women. All patients were asymptomatic and had no signs of tuberculosis after the end of the chemotherapy. Other authors also agreed that tubal block is the sequel of genital tuberculosis, leading to infertility. Among 60 patients with female genital TB, $60 \%$ had primary sub-fertility and $40 \%$ had secondary sub-fertility. Most common tubal pathology was adhesion (36\%). There was bilateral tubal block in $60 \%$ and unilateral tubal block in $40 \%$ of patients [50].

\section{Most common adverse effects of anti-TB therapy}

Long-term exposure to anti-tuberculosis medication increases risk of adverse drug reactions and toxicity. The liver is vulnerable to injury from the first line anti-tuberculosis drugs [51]. Anti-tuberculosis (antiTB) drug induced hepatotoxicity is the most common side effect leading to interruption of therapy. This may result in mortality, long term morbidity and reduced compliance to therapy. Older age, poor nutritional status including baseline hypoalbuminaemia were independent predictors of development of anti-TB hepatitis [52]. In another study old age, anemia, MDR-TB medication, overweight/obesity status, and smoking history were independent risk factors associated with anti-tuberculosis adverse drug reactions [53]. 
Linezolid is one of the few drugs that have shown promise in treating extensively drug-resistant (XDR) tuberculosis and multidrug resistant (MDR) tuberculosis. Long-term linezolid use is associated with toxicities such as peripheral and optic neuropathies. Diabetes mellitus, especially when uncontrolled, can also result in peripheral neuropathy, if a patient receives linezolid [54].

\section{Negative influence of tuberculosis and anti-TB therapy on sexual function}

Not only genital TB negatively influences on female reproductive function, pulmonary TB as well caused menstrual abnormalities in $66 \%$ of women. After completing anti-tuberculosis treatment, $76 \%$ of women with menstrual abnormalities resumed normal menstrual cycles $[55,56]$.

Anti-TB treatment has a negative effect on the ejaculate: a twomonth course of anti-TB therapy resulted in a decrease of sperm quantity $23.9 \%$, decreased a number of actively motile sperm by $10.6 \%$ and the number of morphologically normal sperm-by $32.3 \%$ [57]. To evaluate sexual function, 98 pulmonary TB male patients were enrolled in retrospective study. The intravaginal latency time was estimated before debut of TB and in 3 months of anti-TB therapy. On base-line $14.3 \%$ of pulmonary TB patients had ejaculatory disorders: $10.2 \%$ had premature ejaculation, and $4.1 \%$ delayed ejaculation. The rest $85.7 \%$ of patients had normal ejaculation [58,59]. After three months of the therapy with 4 anti-TB drugs (isoniazid, rifampicin, pyrazinamide and streptomycin) the spectrum of sexual dysfunction changed significantly. The share of patients with normal ejaculation decreased to $61.2 \%$, and frequency of premature ejaculation increased twice (20.4\%), and delayed ejaculation was diagnosed in 4.5 times more often (18.4\%) [58].

Authors emphasized that proportion of ejaculatory disorders in male patients with pulmonary TB initially was the same as in population as whole. They concluded that tuberculosis as a disease doesn't influence on ejaculatory function. But anti-TB therapy with four drugs during three months significantly worsened the ejaculatory function for every forth patient. Authors explained a quadruple increase of frequency of delayed ejaculation by neurotoxicity of some anti-TB drugs. So, tuberculosis as a disease doesn't damage an ejaculatory function, but anti-TB therapy does it. There is necessary a special pathogenetic therapy to prevent this complication [58].

In Russia and especially in Siberia there is an epidemic of TB [9-11]. About two thirds of new revealed patients are young men, and sexual function including reproductive one is very important for them. A sexual function was estimated in 105 new revealed patients with pulmonary tuberculosis aged of 18 to 39 years [59].

Pulmonary TB patients showed deterioration of all parameters of copulatory act, from sexual desire to orgasm, in spite of absence of any related diseases of urogenital system. Patients with widespread cavernous pulmonary TB had higher level of sexual dysfunction than patients with small forms of pulmonary $\mathrm{TB}$, and this level had strong correlation with a severity of intoxication syndrome.

Complex anti-TB chemotherapy improved fertility of pulmonary TB patients by arresting the systematic inflammation and reducing intoxication, but even after 6 months of the treatment they had significantly low scores on the scale of estimation of sexual function and were far from norm [59].

\section{Conclusion}

Tuberculosis disrupts sexual function including reproductive one in male and female patients-both genital TB and pulmonary TB. TB patients have to take not less than 4 anti-TB drugs simultaneously for a long time and anti-TB drugs negatively influence on sexual function too. It is necessary to have high index of suspicion for in-time diagnosis of genital TB, because infertility may be a first symptom of this disease. Protective pathogenetic therapy is indicated for TB patients.

\section{References}

1. Kumar V, Patel S, Jain R (2017) New structural classes of antituberculosis agents. Med Res Rev.

2. WHO Global tuberculosis report 2015

3. WHO Global tuberculosis report 2013

4. Tuberculosis. Fact sheet $\mathrm{N}^{\circ} 104$ Reviewed March 2016. Key facts.

5. WHO Fact sheet $\mathrm{N}^{\circ} 104$ Reviewed March 2017

6. Yadav S, Singh P, Hemal A, Kumar R (2017) Genital tuberculosis: current status of diagnosis and management. Transl Androl Urol 6: 222-233.

7. Kamyshan IS (2003) Guideline on urogenital tuberculosis. Kiev pp: $363-424$

8. Aphonin AB, Perezmanas EO, Toporkova EE, Khodakovsky EP (2006) Tuberculous infection as sexually transmitted infection. Vestnik poslediplomnogo obrazovaniya 3-4: 69-71.

9. Kulchavenya E, Naber K, Johansen TEB (2016) Urogenital tuberculosis: classification, diagnosis and treatment. Europ Urol Supplem 15: 112-121.

10. Kulchavenya E, Khomyakov V (2006) Male genital tuberculosis in siberians. World J Urol 24: 74-78.

11. Kulchavenya E. Best practice in the diagnosis and management of Urogenital Tuberculosis. Ther Adv Urol 5: 143-151.

12. Plata M, Caicedo JI, Trujillo CG, Mariño-Alvarez ÁM, Fernandez N, et al (2017) Prevalence of metabolic syndrome and its association with lower urinary tract symptoms and sexual function. Actas Urol Esp S0210-4806: 30017-7.

13. Minami H, Furukawa S, Sakai T, Niiya T, Miyaoka H, et al. (2017) Physical activity and prevalence of erectile dysfunction in Japanese patients with type 2 diabetes mellitus: The Dogo Study. J Diabetes Investig.

14. Lane-Cordova AD, Kershaw K, Liu K, Herrington D, Lloyd-Jones DM (2017) Association between cardiovascular health and endothelial function with future erectile dysfunction: the multi-ethnic study of atherosclerosis. Am J Hypertens 30: 815-821.

15. Salama N, Eid A, Swedan A, Hatem A (2017) Increased prevalence of premature ejaculation in men with metabolic syndrome. Aging Male 20: 85-95.

16. Said K, Hella J, Mhalu G, Chiryankubi M, Masika E, et al. (2017) Diagnostic delay and associated factors among patients with pulmonary tuberculosis in Dar es Salaam, Tanzania. Infect Dis Poverty 6: 64.

17. Min GH, Kim Y, Lee JS, Oh JY, Hur GY, et al. (2017) Social and clinical characteristics of immigrants with tuberculosis in South Korea. Yonsei Med J 58: 592-597.

18. Feng JY, Jarlsberg LG, Salcedo K, Rose J, Janes M, et al. (2017) Clinical and bacteriological characteristics associated with clustering of multidrug-resistant tuberculosis. Int J Tuberc Lung Dis 21: 766-773.

19. Witkowska-Zimny M, Gunerka A, Wietrak E, Południewski G, LewStarowicz Z (2013) Verification of the effectiveness of the dietary supplementation in infertility treatment. Pol Merkur Lekarski 35: 347-351.

20. Showell MG, Brown J, Clarke J, Hart RJ (2013) Antioxidants for female subfertility. Cochrane Database Syst Rev.

21. Olsen J, Ramlau-Hansen CH (2014) Epidemiologic methods for investigating male fecundity. Asian J Androl 16: 17-22. 
22. Olsen J, Zhu JL, Ramlau-Hansen CH (2011) Has fertility declined in recent decades? 90: 129-135.

23. Jørgensen N, Joensen UN, Jensen TK, Jensen MB, Almstrup K, et al. (2012) Human semen quality in the new millennium: a prospective crosssectional population-based study of 4867 men. BMJ Open 2.

24. Dada R, Kumar M, Jesudasan R, Fernández JL, Gosálvez J (2012) Epigenetics and its role in male infertility. J Assist Reproduct Geneti 29: 213-223.

25. Jurewicz J, Hanke W, Radwan M, Bonde J (2009) Environmental factors and semen quality. Int J Occup Med Environ Health 22: 305-329.

26. Zhang SH, Zhu HB, Li LL, Yu Y, Zhang HG (2013) Decline of semen quality and increase of leukocytes with cigarette smoking in infertile men. Iran J Reprod Med 11: 589-596.

27. Showell MG, Brown J, Yazdani A, Stankiewicz MT, Hart RJ (2011) Antioxidants for male subfertility. Cochrane Database Syst Rev 19.

28. Ramlau-Hansen CH, Toft G, Jensen MS, Strandberg-Larsen K, Hansen ML, et al. (2010) Maternal alcohol consumption during pregnancy and semen quality in the male offspring: two decades of follow-up. Hum Reprod 25: 2340-2345.

29. Nordkap L, Joensen UN, Blomberg Jensen M, Jørgensen N (2011) Regional differences and temporal trends in male reproductive health disorders: semen quality may be a sensitive marker of environmental exposures. Mol Cell Endocrinol 355: 221-230.

30. Dohle GR (2003) Inflammatory-associated obstructions of the male reproductive tract. Andrologia 35: 321-324.

31. Kondoh N, Fujimoto M, Takeyama M, Nakamura Y, Kitamura M, et al. (1999) Treatment of azoospermic patient with genitourinary tuberculosis: a case report. Hinyokika Kiyo Acta Urologica Japonica 45: 199-201.

32. Mateos Colino A, Sousa Escandón MA, Golpe Gómez R, García Figueras R, Pérez Valcarcel J, et al. (2003) Tuberculous epididymitis caused by Mycobacterium bovis. Arch Espano Urol 56: 175-178.

33. Moon SY, Kim SH, Jee BC, Jung BJ, Suh CS, et al. (1999) The outcome of sperm retrieval and intracytoplasmic sperm injection in patients with obstructive azoospermia: impact of previous tuberculous epididymitis. J Assist Reprod Genet 1999 16: 431-435.

34. Indudhara R, Das K, Sharma M, Vaidyanathan S (1991) Seminal vesiculitis due to Mycobacterium gastri leading to male infertility. Urol Int 46: 99-100.

35. Chung JJ, Kim MJ, Lee T, Yoo HS, Lee JT (1997) Sonographic findings in tuberculous epididymitis and epididymo-orchitis. J Clin Ultrasound 25: 390-394.

36. Gueye SM, Ba M, Sylla C, Ndoye A, Fall A, et al. (1996) Epididymal manifestations of urogenital tuberculosis. Dakar Med 41: 55-58.

37. Lübbe J, Ruef C, Spirig W, Dubs M, Sigg C (1996) Infertility as the first symptom of male genitourinary tuberculosis. Urol Interna 56: 204-206.

38. Colino AM, Escandón MAS, Gómez RG, Figueras RG, Valcarcel JP, et al. (2003) Tuberculous epididymitis caused by Mycobacterium bovis Arch Esp Urol 56: 175-178.

39. Fraietta R, Mori MM, De Oliveira JMA, Cedenho AP, Srougi M (2003) Tuberculosis of seminal vesicles as a cause of aspermia. J Urol 169: 1472.

40. Gorse GJ, Belshe RB (1985) Male genital tuberculosis: a review of the literature with instructive case reports. Rev Infect Dis 7: 511-524.
41. Jiménez-Cruz JF, De Cabezon JS, Soler-Rosello A, Sole-Balcells F (1979) The spermiogram in urogenital tuberculosis. Androl 11: 67-70.

42. Sole-Balcells F, Jimenez-Cruz F, de Cabezon JS, Rosello AS (1977) Tuberculosis and infertility in men. Eus Urol 3: 129-131.

43. Kumar R, Hemal AK (2004) Bilateral epididymal masses with infertility. ANZ J Surg 74: 391.

44. Tzvetkov D, Tzvetkova P (2006) Tuberculosis of male genital system-myth or reality in 21st century. Arch Androl 52: 375-381.

45. Sheikh HH (1994) Infertility due to genital tuberculosis. J Am Assoc Gynecol Laparosc 4.

46. Gupta N, Sharma JB, Mittal S, Singh N, Misra R, et al. (2007) Genital tuberculosis in Indian infertility patients. Int J Gynaecol Obstet 97: 135-138.

47. Singh N, Sumana G, Mittal S (2008) Genital tuberculosis: a leading cause for infertility in women seeking assisted conception in North India. Arch Gynecol Obstet 278: 325-327.

48. Parikh FR, Nadkarni SG, Kamat SA, Naik N, Soonawala SB, et al. (1997) Genital tuberculosis-a major pelvic factor causing infertility in Indian women. Fertil Steril 67: 497-500.

49. Tripathy SN (2002) Infertility and pregnancy outcome in female genital tuberculosis. Int J Gynaecol Obstet 76: 159-163.

50. Banu J, Begum SR, Fatima P (2009) Association of pelvic tuberculosis with tubal factor infertility. Mymensingh Med J 18: 52-55.

51. Aishatu G, Rasheedah I, Wahab J, Sheni M, Damilola O, et al. (2017) Hsepatotoxicity due to antituberculosis therapy among paediatric patients seen at the university of Ilorin teaching hospital, North Central Nigeria. Ethiop J Health Sci 27: 115-120.

52. Singla R, Sharma SK, Mohan A, Makharia G, Sreenivas V, et al. (2010) Evaluation of risk factors for antituberculosis treatment induced hepatotoxicity. Ind J Med Res 132: 81-86.

53. Chung-Delgado K, Revilla-Montag A, Guillen-Bravo S, Velez-Segovia E, Soria-Montoya A, et al. (2011) Factors associated with anti-tuberculosis medication adverse effects: a case-control study in Lima, Peru. PLoS One 6: e27610.

54. Swaminathan A, du Cros P, Seddon JA, Mirgayosieva S, Asladdin R, et al. (2017) Peripheral neuropathy in a diabetic child treated with linezolid for multidrug-resistant tuberculosis: a case report and review of the literature. BMC Infect Dis Jun 17: 417.

55. Hassan WA, Darwish AM (2010) Impact of pulmonary tuberculosis on menstrual pattern and fertility. Clin Respir J 4: 157-161.

56. Hassan WA, Darwish AM (2009) Impact of pulmonary tuberculosis on menstrual pattern and fertility. Chest 136.

57. Kulchavenya EV, Osadchii AV (2016) The role of pathogenetic therapy in preserving ejaculate fertility in patients with tuberculosis of prostate. Urologiia. pp: 14-18.

58. Kulchavenya E, Medvedev S (2011) Therapy for pulmonary tuberculosis as a reason for ejaculatory disorders. J Sex Med 8: 384-405.

59. Kulchavenya E, Scherban M, Brizhatyuk E, Osadchiy A (2012) Sexual dysfunction in male patients with pulmonary tuberculosis. J Microbiol Infect Dis 2: 124-126. 